\title{
Antimicrobial activity of Melaleuca sp. oil against clinical isolates of antibiotics resistant Staphylococcus aureus ${ }^{1}$
}

\author{
Sávia Perina Portilho Falci ${ }^{\mathrm{I}}$, Manoel Araujo Teixeira ${ }^{\mathrm{II}}$, Pablo Ferreira das Chagas ${ }^{\mathrm{II}}$, Beatriz Bertolaccini Martinez ${ }^{\mathrm{IV}}$, Ana \\ Beatriz Alkmim Teixeira Loyola ${ }^{\mathrm{V}}$, Lydia Masako Ferreira ${ }^{\mathrm{VI}}$, Daniela Francescato Veiga ${ }^{\mathrm{VII}}$
}

\author{
DOI: http://dx.doi.org/10.1590/S0102-865020150060000005
}

IFellow Master degree, Postgraduate Program in Sciences Applied to Health, Vale do Sapucai University (UNIVAS), Pouso Alegre-MG, Brazil. Acquisition, analysis and interpretation of data; manuscript writing.

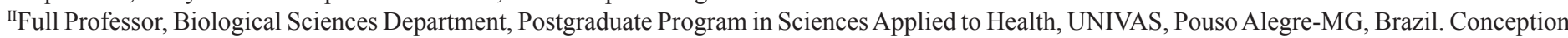
and design of the study; acquisition, analysis and interpretation of data; manuscript writing; critical revision.

II'Undergraduate student, Biological Sciences School, UNIVAS, Pouso Alegre-MG, Brazil. Acquisition of data, manuscript writing, critical revision.

${ }^{\mathrm{IV}}$ Full Professor, Medical Physiology Division, Postgraduate Program in Sciences Applied to Health, UNIVAS, Pouso Alegre-MG, Brazil. Conception and design of the study, manuscript writing, critical revision.

vAssociate Professor, Pharmacy Department, Postgraduate Program in Sciences Applied to Health, UNIVAS, Pouso Alegre-MG, Brazil. Analysis and interpretation of data, manuscript writing.

${ }^{\mathrm{V}}$ Head and Full Professor, Plastic Surgery Division, Department of Surgery, Postgraduate Program in Translational Surgery, Sao Paulo Federal University (UNIFESP), Sao Paulo-SP, Brazil. Manuscript writing, critical revision.

${ }^{\mathrm{VII}}$ Associate Professor, Postgraduate Program in Translational Surgery, UNIFESP, and Professional Masters in Sciences Applied to Health, UNIVAS, Pouso Alegre-MG. Manuscript writing, critical revision.

\section{ABSTRACT}

PURPOSE: To extract the Melaleuca sp. oil and to assess its in vitro inhibitory effect against Staphylococcus aureus isolates obtained from lower limb wounds and resistant to several antibiotics.

METHODS: A total of 14 test-tubes containing Mueller-Hinton broth were used to determine the Minimum Inhibitory Concentration (MIC). The following concentrations of the Melaleuca sp. oil were added to the first 11 tubes: $8 ; 4 ; 2 ; 1 ; 0.5 ; 0.2 ; 0.1 ; 0.05 ; 0.025$; 0,0125 and $0.00625 \%$. The $12^{\text {th }}$ and $13^{\text {th }}$ tubes, with and without oil, were used as the positive and negative controls, respectively. The experimental study was carried out in triplicate at $37^{\circ} \mathrm{C}$ for 18 hours. The Minimum Bactericidal Concentration (MBC), able of killing all the microorganisms, was also determined. Two $S$. aureus isolates were obtained from lower limb wounds of female patients and the identification of the microorganisms (Staphylococcus aureus) and the test for susceptibility to the antimicrobial agents were carried out by automation using the apparatus MicroScan ${ }^{\circledR}$. After identification, the isolates were preserved in liquid Trypticase Soy medium, and inoculated for determination of the MIC and MBC.

RESULTS: The MIC was $0.2 \%$ and the MBC was $0.4 \%$.

CONCLUSION: The Melaleuca sp. oil showed antimicrobial properties in vitro against strains isolated from lower limb wounds which were resistant to multiple antibiotics.

Key words: Phytotherapy. Tea Tree Oil. Staphylococcus aureus. in Vitro Techniques. Injuries. 


\section{Introduction}

Staphylococcus aureus are pathogenic microorganisms responsible for a mortality superior to that caused by AIDS, tuberculosis and viral hepatitis together in the United States of America ${ }^{1}$. They are commonly found associated with surgical site infections and several other clinical implications ${ }^{2}$. The presence of infectious microorganisms is a major cause of fail on wound healing ${ }^{3}$.

The indiscriminate use of antibiotics against staphylococcal infections has been a practice used throughout the world, which has resulted in an increase in methicillin-resistant Staphylococcus aureus (MRSA) and other antimicrobial resistance profiles ${ }^{4}$.

Research into the medicinal action of essential oils from some plants is becoming more popular, since many synthetic drugs are related to undesirable collateral effects, such as nephrotoxicity and ototoxicity ${ }^{5}$ Among the studied herbal substances, the plant known as the "tea tree" (Melaleuca alternifólia Cheel) is one of the most important, since it has already shown action against MRSA, coagulase-negative streptococcus and staphylococcus and coliforms ${ }^{6-8}$.

Australia was pioneer in the use of Melaleuca alternifólia oil (TTO), but many other species can be found around the world ${ }^{9}$. Species of Melaleuca armillaris, M. acuminata and $M$. stypheloiodes are cultivated in Tunisia ${ }^{10}$, and oils from species of M. ericifolia, M. leucadendron, M. armillaris and M. styphelioides have been extracted in Egypt ${ }^{11}$. The use of M. leucadendron has been described in western Malaysia and Vietnam and Melaleuca quinquenervia in the $\mathrm{USA}^{12,13}$. Although the oil of M. alternifólia is the most commercialized one throughout the world, the water distillation of other species can produce oils with similar constitutions, such as $M$. linariifolia and $M$. dissitifloria ${ }^{14}$.

The action of Melaleuca alternifólia oil was studied using transcription profiles for a better understanding of the activity of TTO on $S$. aureus strains ${ }^{15}$. This research showed that the action could be constituted not only of a mechanism, but also by an action with multi-component characteristics mainly affecting the cell wall ${ }^{15}$. These results corroborated other authors findings, which described the bactericidal activity of TTO as being attributed to its ability to denature proteins and alter the structure and function of the cell wall membrane $e^{9,16-18}$.

Studies have been carried out with the species $M$. hypericifolia and M. thymifolia in Brazil, at the Federal University of Viçosa ${ }^{17}$. The Melaleuca sp. are cultivated as ornamental plants in the city of Pouso Alegre, in the south of the state of Minas Gerais, and the oil extracted from these plants could have properties equal or similar to that extracted from M. alternifólia, but at a lower cost, since it is cultivated in Brazil. Thus, the aim of the present study was to extract the oil from Melaleuca sp. and to assess the in vitro inhibitory effect of this oil against Staphylococcus aureus obtained from lower limb wounds, which were resistant to several antibiotics.

\section{Methods}

\section{Extraction and identification of the chemical properties of the essential oil from Melaleuca sp}

The oil was extracted from the plant leaves by water distillation using Clevenger type equipment (Hermex Glassware - Brazil). After extraction, it was stored in dark flasks in a refrigerator at $5^{\circ} \mathrm{C}$. The chemical properties were identified by gas chromatography using a model 7890 gas chromatograph (Agilent, USA) coupled to a model 5975 linear quadrupole type mass spectrophotometer (Agilent, USA). The oil components were identified based on the NIST11 mass spectra data (Agilent, USA) and on the Automated Mass Spectral Deconvolution Mass and Identification System (Agilent - USA). The concentration of the compounds was expressed as a percentage of the normalized peak area (each separated substance appeared as a peak on the chromatogram). The index adopted for quality was above $70 \%$.

\section{Isolation and tests with Staphyloccus aureus. bacterial samples}

Two $S$. aureus isolates were obtained from lower limb wounds of female patients aged 36 and 57 years-old, located on the foot and knee, respectively. The isolate from the foot wound was resistant to the antibiotics Amoxicillin/Clavulanic acid, Ampicillin/Sulbactam, Ceftriaxone, Erythromycin, Oxacillin, Penicillin and Tetracyclin. The resistance was intermediary for the antibiotic Clindamycin. The isolate from the knee wound was resistant to the antibiotics Amoxicillin/Clavulanic acid, Ampicillin/Sulbactam, Ceftriaxone, Ciprofloxacin, Clindamycin, Erythromycin, Levofloxacin, Moxifloxacin, Oxacillin, Penicillin and Synercid.

Identification of the microorganisms (Staphylococcus aureus) and the test for susceptibility to the antimicrobial agents were carried out by automation using the apparatus MicroScan ${ }^{\circledR}$ 
auto SCAN-4 System (Siemens, Germany) with the use of the com Pos Combo Type 41 panel (Siemens, Germany), and seeding was carried out using various slopes as the stock cultures, from which they were reactivated and inoculated for determination of the Minimum Inhibitory Concentration (MIC) and Minimum Bactericidal Concentration (MBC).

\section{Determination of the Minimum Inhibitory Concentration (MIC)}

From the stock cultures, the Staphylococci were transferred to the Thioglycollate medium (Himedia ${ }^{\circledR}$ ), incubated at $37^{\circ} \mathrm{C}$ for 24 hours and then spread on a mannitol salt agar medium and then again incubated at $37^{\circ} \mathrm{C}$ for 24 hours. The concentration for the inoculation of each species of $S$. aureus was $1 \times 10^{6} \mathrm{CFU}$ (colony forming units) $/ \mathrm{mL}$ and it was obtained using a sterile swab, which was touched on the surface of 4 to 5 great colonies isolated in the mannitol salt agar plate and emulsified in $3 \mathrm{~mL}$ of water for the inoculum (autoclaved deionized water). The final turbidity was equivalent to a 0.5 McFarland turbidity standard. The turbidity was confirmed by the use of the MicroScan ${ }^{\circledR}$ turbidity meter with an interval of $0.08 \pm 0.02$ (Procedure manual for Gram-Positive Dehydrated Panels-MicroSan ${ }^{\circledR}$-SIEMENS Panels).

The microorganisms were transferred to Thioglycolate medium (Himedia ${ }^{\circledR}$ ) and incubated at $37^{\circ} \mathrm{C}$. Fourteen test tubes, each one containing $5 \mathrm{~mL}$ of Mueller-Hinton broth (MHB - Difco $\mathrm{Co}$ ), were used to determine the MIC of each isolate. Progressive concentrations of the extracted oil were added to 12 tubes, the $12^{\text {th }}$ tube being used as the control (smallest oil concentration, no inoculum). The $13^{\text {th }}$ tube was used as the positive growth control (no oil, with inoculum) and the $14^{\text {th }}$ tube was used as the negative control (no oil and no inoculum, just the culture medium). The MIC was established for the bacteria isolated from the two lower limb wounds and for the strain Staphylococcus aureus subsp. aureus (ATCC $\AA 25923^{\mathrm{TM}}$ ), which is a standard American strain.

The oil concentrations used were: $8 ; 4 ; 2 ; 1 ; 0.4 ; 0.2 ; 0.1$; $0.05 ; 0.025 ; 0.0125$ and $0.00625 \%$ and for each tube the assay was carried out in triplicate. After adding the oil, the first 11 tubes (including the positive control) received $250 \mu \mathrm{L}$ of inoculum at a concentration of $1 \times 10^{6} \mathrm{CFU} / \mathrm{mL}$. All the tubes were incubated at $37^{\circ} \mathrm{C}$ for 18 hours and then each tube examined visually for the presence of turbidity. The first tube showing turbidity was considered to be that containing the MIC. To enable the solubility of the oils tested in the medium culture, a Tween 80 was used, because this kept the oil soluble for a longer period of time required to perform the tests thus making it efficient. The concentration that was used in the experiments was $5 \mu \mathrm{L} / \mathrm{mL}$ of the final concentration in the culture medium.

\section{Determination of the Minimum Bactericidal Concentration $(M B C)$}

Aliquots of $5 \mu \mathrm{L}$ were removed from the tubes showing no turbidity and used to seed Petri dishes containing mannitol salt agar (Difco Co. - USA). The lower concentration which not allowed the growth of any colonies on the agar surface was considered to be the $\mathrm{MBC}$, that is, the concentration able to kill all the microorganisms.

\section{Results}

A total of 27 peaks were detected in the Melaleuca sp. oil, of which 21 are presented in Table 1. The six unidentified peaks could be related to new structures that were not recognized by the data library of the program, or could be peaks that do not separate from the others. There was a slight prevalence of monoterpenes $(57.2 \%)$ in relation to sesquiterpenes $(42.8 \%)$. The main monoterpenes were eucalyptol or 1.8 cineol with $70.8 \%$, followed by terpineol with $8.95 \%$ and limonene with $8.25 \%$. Of the sesquiterpenes encountered the most abundant was globulol followed by octahydrotetramethyl with $0.82 \%$ and $0.62 \%$, respectively.

The values obtained for the MIC and MBC were respectively $0.1 \%$ and $0.4 \%$ for the $S$. aureus isolate obtained from the foot wound, and $0.2 \%$ and $0.4 \%$ for the isolate from the knee 
TABLE 1 - Compounds detected in the Melaleuca sp. oil sample.

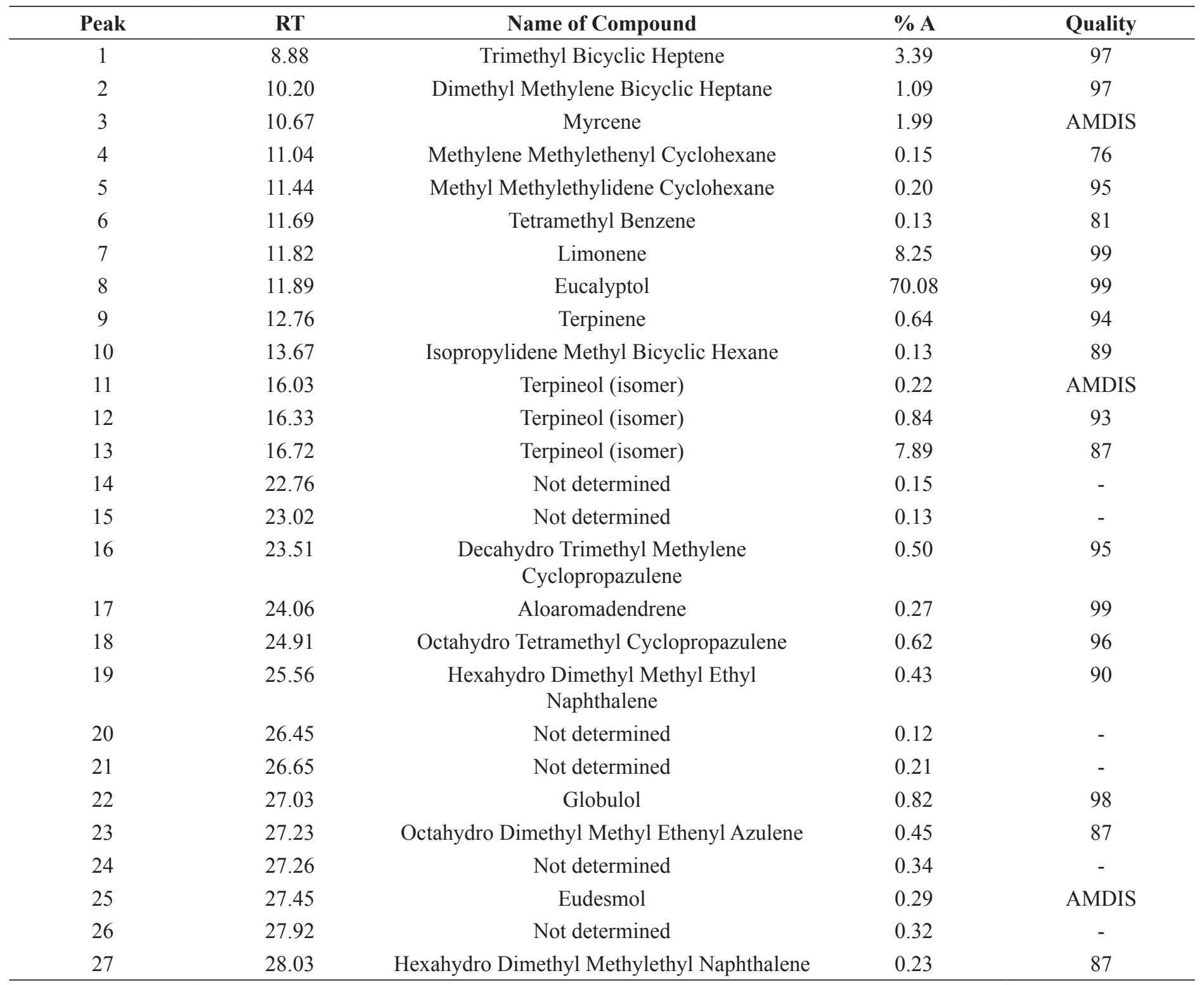

Peak: Peak number according to elution order from the column.

RT: Retention time from the column in minutes.

Name of compound: Most common name of compound identified.

\%A: Percentage of normalized area which indicates the relative distribution of the compounds in the sample.

Quality: this is the search index in the database that reflects the similarity of the mass spectrum obtained with those registered in the libraries used. Quality indexes $>70$ were adopted.

AMDIS: Automated Mass Spectral Deconvolution Mass and identification System.

wound. For the strain $\mathrm{ATCC}^{\circledR} 25923^{\mathrm{TM}}$ the MIC and MBC were respectively $0.2 \%$ and $0.4 \%$.

\section{Discussion}

Carson et al. ${ }^{9}$ reported that the oil isolated from the tea tree (M. alternifolia) was constituted of terpene hydrocarbons, mainly monoterpenes, sesquiterpenes and other associated alcohols. The same was observed in the present study with very similar percentages. Nevertheless, comparing the compounds of the two plants, Melaleuca sp. and M. alternifolia, differences can be found in the constitutions of the oils, such as a prevalence of eucalyptol (1.8 cineol) in the Brazilian sample and terpinen-4-ol as the main constituent described in the Australian samples ${ }^{9}$.

One of the difficulties of establishing phytotherapy as a medical practice is the lack of standardization of the chemical constituents of the plants. This has frequently been reported in the literature, and other authors have described the variations in the 
constituents of Melaleuca alternifolia oil, even when using the same varieties or chemotypes or even from different samples ${ }^{9,19}$. The oil extracted from Melaleuca sp. is rich in eucalyptol (1.8 cineol) and, in recent years, research has attributed antimicrobial action to this molecule, which acts by facilitating permeability of the membranes of microorganisms such as $S$. aureus ${ }^{9}$. The eucalyptol found in the Brazilian sample opens the possibility for future studies on the action of this substance against pathogenic bacteria, particularly those of the genus $S$. aureus. In fact, in vitro, its action was just as efficient as the oils cultivated in Australia, which have terpinen-4-ol as the main antimicrobial agent.

Data related to the MIC and MBC were also obtained by Cox et al. ${ }^{16}$ when they studied the action of the tea tree against $E$. coli (AG100) and S. aureus (NCTC 8325). The MIC obtained by these authors for the isolate of Staphylococcus aureus (ATCC ${ }^{\circledR} 25923$ ), an oral pathogen, was $0.1 \%$ and the MBC $0.4 \%{ }^{17}$. Other studies have shown that oils rich in monoterpenes and sesquiterpenes have bactericidal and bacteriostatic characteristics ${ }^{20,21}$. The Melaleuca sp. oil controlled the bacterial strains in a highly efficient way at a very low concentration, showing itself to be a good antimicrobial agent.

Possibly the $S$. aureus isolates are not always inhibited by such low doses of the Melaleuca sp. oil, since results for the susceptibility observed in 20 clinical MRSA samples, obtained from South Korean patients, showed values for MIC and MBC much higher than those observed in the present study ${ }^{21}$. In this same line of research, the MICs of 13 essential oils were evaluated in relation to 65 bacterial strains, amongst which $S$. aureus, including two metacycline susceptible strains and five methicillin susceptible strains $^{22}$. These authors classified the oils based on their antimicrobial activities in relation to the genus Staphylococcus. The oil from the Melaleuca alternifolia was included in the group showing bactericidal activity at concentrations above $2 \%$ after 24 hours $^{22}$. They also showed that other types of essential oil showed greater bactericidal activity, in which the action occurred at concentrations equal or below $2 \%$ and in a time not exceeding 30 minutes ${ }^{22}$.

Since 1990s, studies with plants from the genus Melaleuca have foccused on their bactericidal action against microorganisms that had acquired antibiotic resistance, principally the methicillinresistant $S$. aureus $^{9}$. The search for active principles with the capacity to substitute common antibiotics, to which many strains of microorganisms already show resistance, has been one of the priorities on the current world scenario.

\section{Conclusion}

Melaleuca sp. oil extracted in Brazil showed bactericidal potential in vitro against the bacterial isolates obtained from lower limb wounds and also to the standard S. aureus strain (ATCC ${ }^{\circledR} 25923^{\mathrm{TM}}$ ).

\section{References}

1. Boucher HW, Corey GR. Epidemiology of methicillin-resistant Staphylococcus aureus. Clin Infect Dis. 2008;46:344-9. doi: $10.1086 / 533590$.

2. Van Hal SJ, Jensen SO, Vaska VL, Espedido BA, Paterson DL, Gosbell IB. Predictors of mortality in Staphylococcus aureus bacteremia. Clin Microbiol Rev. 2012;25:362-86. doi: 10.1128/ CMR.05022-11.

3. Manring MM, Hawk A, Calhoun JH, Andersen RC. Treatment of war wounds. A historical review. Clin Orthop Relat Res. 2009;467:216891. doi: 10.1007/s11999-009-0738-5.

4. Friedrich AW. Patient safety - mission for the future - Healthcareassociated infections and antibiotic resistances. Anasthesiol Intensivmed Notfallmed Schmerzther. 2014;49:474-82. doi: 10.1055/s-0034-1386710.

5. Lang G, Buchbauer G. A review on recent research results (20082010) on essential oils as antimicrobials and antifungals. A review. Flavour Frag J. 2012;27:13-39. doi: 10.1002/ffj.2082.

6. Carson CF, Cookson BD, Farrelly HD, Riley TV. Susceptibility of methicillin-resistant Staphylococcus aureus to the essential oil of Melaleuca alternifolia. J Antimicrob Chemoter. 1995;35:421-4. PMID: 7782258.

7. Carson CF, Hammer KA, Riley TV. In-vitro activity of the essential oil of Melaleuca alternifolia against Streptococcus spp. J Antimicrob Chemother. 1996;7:1177-8. PMID: 8836821.

8. Hammer KA, Carson CF, Riley TV. Susceptibility of transient and commensal skin flora to the essential oil of Melaleuca alternifolia (tea tree oil). Am J Infect Control. 1996;24:186-9. PMID: 8806995.

9. Carson CF, Hammer KA, Riley TV. Melaleuca alternifólia (tea tree) oil: a review of antimicrobial and other medicinal properties. Clin Microbiol Rev. 2006;19:50-62. PMID: 16418522.

10. Amri I, Mancini E, Martino L, Marandino A, Lamia H, Molshen H, Bassen J, Scognamiglio M, Reverchon E, Feo V. Chemical composition and biological activities of essential oil from tree Melaleuca species grown in Tunisia. Int J Mol Sci. 2012;13:1658091. PMID: 23443119.

11. Farag RS, Shalaby AS, El-Baroty GA, Ibrahim NA, Ali MA, Hassan EM. Chemical and biological evaluation of the essential oils of different Melaleuca species. Phytother Res. 2004;18:30-5. PMID: 14750197.

12. Brinkman WJ, Xuan VT. Melaleuca leucadendron, a useful and versatile tree for acid sulphate soils and some other poor environments. Int Tree Crops J. 1991;6:261-74. doi: 10.1080/01435698.1991.9752891.

13. Porazinska DL, Pratt PD, Glblin-Davis RM. Consequences of Melaleuca quinquenervia Invasion on Soil Nematodes in the Florida Everglades. J Nematol. 2007;39:305-12. PMID: 19259503.

14. Arbujai T, Natsheh FM. Planted ued in cosmetics. Phytother Res. 2003;17:987-1000. PMID: 14595575 .

15. Cuaron JA, Dulal S, Song Y, Singh AK, Montelongo CE, Yu W, Nagarajan V, Jayaswal RK, Wilkinson BJ, Gustafson, JE. Tea tree oil-induced transcriptional alterations in Staphylococcus aureus. Phytother Res. 2013;27:390-6. PMID: 22619070.

16. Cox SD, Mann CM, Markham JL, Bell HC, Gustafson JE, Warmington JR, Wyllie SG. The mode of antimicrobial action of the essential oil of Melaleuca alternifolia (tea tree oil). J Appl Microbiol. 2000;88:170-5. PMID: 10735256. 
17. Thosar N, Basak S, Bahadure RN, Rajurkar M. Antimicrobial efficacy of five essential oils against oral pathogens: an in vitro study. Eur J Dent. 2013;7:71-7. PMID: 24966732.

18. Gustafson JE, Liew YC, Chew S, Effectsof tea tree oil on Escherichia coli. Lett Appl Microbiol. 1998;26:194-8. PMID: 9569708.

19. Sikemma J, de Bont JA, Poolman B. Mechanisms of membrane toxicity of hidrocarbons. Microbiol Rev.1995; 59:201-22. PMID: 7603409.

20. Silva CJ, Barbosa LCA, Demuner AJ, Montanari RM, Pinheiro AL, Dias I, Andrade NJ. Chemical composition and antibacterial activities from the essential oils of Myrtaceae species planted in Brazil. Quím Nova. 2010;33:104-8. doi: 10.1590/S0100-40422010000100019.

21. Park H, Jang C, Cho YB, Choi C. Antibacterial effect of tea-tree oil on methicillin-resistant Staphylococcus aureus biofilm formation of the tympanostomy tube: an in vitro study. In vivo. 2007;21:1027-30. PMID: 18210750.

22. Mayaud L, Carricajo A, Zihri A, Aubert G. Comparison of bacteriostatic and bactericidal activity of 13 essential oil against strains with varying sensitivity to antibiotics. Lett Appl Microbiol. 2008;47:167-73. PMID: 19552780.

\section{Correspondence:}

Manoel Araújo Teixeira

Programa de Pós-graduação em Ciências Aplicadas à Saúde

UNIVÁS

Avenida Prefeito Tuany Toledo, 470

37550-000 Pouso Alegre - MG Brasil

Tel.: (55 35)3425-2008 / 9105-5851

manoel.at@uol.com.br

Received: Feb 14, 2015

Review: Apr 13, 2015

Accepted: May 14, 2015

Conflict of interest: none

Financial source: none

${ }^{1}$ Research performed at Vale do Sapucai University (UNIVAS), Pouso Alegre-MG, Brazil. Part of Master degree thesis, Professional Masters in Sciences Applied to Health, UNIVAS. Tutor: Manoel Araújo Teixeira. 